\title{
Effects of Myocardial Ischemia-Reperfusion on Autophagy of Brain Cells and the Intervention Effect of Propofol in Type 2 Diabetic Rats
}

\author{
CHU HAN WANG, WEI LI ${ }^{2}$, XIN LI FENG ${ }^{1}$, XIN ZHANG ${ }^{3}$, Q. LI AND H. J. WANG ${ }^{*}$
}

Department of Neurology, ${ }^{1}$ Department of Hyperbaric Oxygen, Affiliated Hospital of Hebei University, No. 212, Yuhua East Road, '2Department of Ultrasonography, ${ }^{3}$ Department of Neurology, BaoDing No. 1, Central Hospital No. 966, Baihua East Road, ${ }^{4}$ College of Basic Medicine, Hebei University No. 342, Yuhua East Road, Lianchi District, Baoding, Hebei 071000, China

Wang et al.: Effects on Autophagy of Brain Cells and Intervention Effect of Propofol in Type 2 Diabetic Rats

To investigate the expression of autophagy markers of brain cells and the effect of propofol on autophagy during myocardial ischemia-reperfusion in type 2 diabetic rats. 36 healthy male Sprague Dawley rats were randomly divided into 6 groups, 6 in each group, fed with high-sugar and high-fat diet for 8 w and intraperitoneal injection of streptozotocin to prepare the rat model of type 2 diabetes. The 6 groups are: diabetic rat with sham operation group, diabetic rat with myocardial ischemia reperfusion group, diabetic rat with myocardial ischemia reperfusion+propofol group, normal rat with sham operation, normal rat with myocardial ischemia reperfusion group, normal rat with myocardial ischemia reperfusion+propofol group. In the normal rat with myocardial ischemia reperfusion+propofol group and diabetic rat with myocardial ischemia reperfusion+propofol group, the left anterior descending coronary artery was ligated for $30 \mathrm{~min}$ and reperfused for $2 \mathrm{~h}$ after the propofol was injected with $6 \mathrm{mg} / \mathrm{kg} / \mathrm{h}$ for 10 min. Normal rat with myocardial ischemia reperfusion group and diabetic rat with myocardial ischemia reperfusion groups were pumped with $3 \mathrm{ml} / \mathrm{kg} / \mathrm{h}$ normal saline for $10 \mathrm{~min}$, followed by ligation of the left anterior descending coronary artery for $30 \mathrm{~min}$ and reperfusion for $\mathbf{2} \mathbf{h}$. Arterial ligation was not performed in the normal rat with sham operation group and diabetic rat with sham operation groups. Brain tissue was taken to detect its levels of mechanistic target of rapamycin, phosphorylated mammalian target of rapamycin and Beclin-1 by Western blot. Compared with normal rat with sham operation group, phosphorylated mammalian target of rapamycin level was significantly decreased, and mechanistic target of rapamycin beclin- 1 expression level was significantly increased in the other 5 groups $(p<0.05)$. Compared with diabetic rat with myocardial ischemia reperfusion group, the expression level of phosphorylated mammalian target of rapamycin in diabetic rat with myocardial ischemia reperfusion+propofol group was increased, while beclin-1 and mechanistic target of rapamycin expression levels were significantly decreased $(\mathbf{p}<\mathbf{0 . 0 5})$. Compared with normal rat with myocardial ischemia reperfusion group, the level of mechanistic target of rapamycin in normal rat with myocardial ischemia reperfusion+propofol group was significantly increased, while the beclin-1 and mechanistic target of rapamycin expression levels were significantly decreased $(p<0.05)$. Diabetes can promote the autophagy of brain cells during myocardial ischemia-reperfusion and aggravate the brain injury. Propofol can up-regulate the level of Phosphorylated mammalian target of rapamycin and down-regulate the expression of mechanistic target of rapamycin to alleviate the damage of brain cells after myocardial ischemia and reperfusion in normal rats and type 2 diabetic rats.

Key words: Myocardial ischemia reperfusion, type 2 diabetes, autophagy, brain cells, propofol

36 healthy male Sprague Dawley (SD) rats, aged 6-8 w and weighing 200-220 g, were randomly divided into two groups $(\mathrm{n}=18)$, which are Non-insulin-dependent (type 2) diabetes group and normal rats group. The type 2 diabetic group was raised with High-fat diet (HFD) feed (formula: $59 \%$ ordinary feed, $20 \%$ sucrose, $10 \%$ lard, $1 \%$ cholesterol, $10 \%$ egg yolk powder) for $8 \mathrm{w}$, and then injected with streptozotocin (STZ) $30 \mathrm{mg} / \mathrm{kg}$ (dissolved in citric acid buffer ( $\mathrm{pH} 4.2 \sim 4.5$ ), pay attention to avoid light), to prepare the type 2 diabetic model. Blood was collected from the tail vein for $12 \mathrm{~h}$ after STZ injection to determine the fasting blood glucose. The type 2 diabetes model was successfully prepared in experimental rats with stable blood glucose 
above $14 \mathrm{mmol} / \mathrm{l}$ and obvious polydipsia and polyuria. The normal rat group was fed with ordinary feed (feed certificate number: SCXK (Ji) 2013-2-001), and were intra peritoneally injected with citric acid buffer solution of $30 \mathrm{mg} / \mathrm{kg}$. The type 2 diabetes group was randomly divided into three groups $(n=6)$ : which are sham operation group (DC group), myocardial ischemia-reperfusion group (DI group), and myocardial ischemia-reperfusion+propofol group DI+P group ${ }^{[1]}$. Each group of rats was given intraperitoneal injection of $10 \%$ chloral hydrate $(350 \mathrm{mg} / \mathrm{kg})$. After successful anesthesia, endotracheal intubation was performed and small animal ventilators were attached for mechanical ventilation. The micro infusion pump of femoral venipuncture is used for propofol infusion (or normal saline). The rat takes the right decubitus position, opens its chest and cuts the pericardium, threads a silk thread under the left anterior descending coronary artery, and placed a polyethylene hard tube between the myocardium and the ligature. It means myocardial ischemia has been successfully prepared when the color of the myocardium below the ligation site becomes dark while tightening the ligation and the electrocardiogram showed significant elevation of interval between ventricular depolarization and ventricular repolarization (ST) segment. The ischemia time is $30 \mathrm{~min}$, the color of the myocardium turns red after the ligature is loosened, and the elevated ST segment drops more than 1/2, indicating successful reperfusion, and the reperfusion time is $2 \mathrm{~h}^{[2]}$. In the normal rat with myocardial ischemia reperfusion+propofol $(\mathrm{CI}+\mathrm{P})$ group and $\mathrm{DI}+\mathrm{P}$ groups, propofol $6 \mathrm{mg} / \mathrm{kg} / \mathrm{h}$ was intravenically pumped $10 \mathrm{~min}$ before ischemia and until the end of $2 \mathrm{~h}$ of reperfusion. The normal rat with myocardial ischemia reperfusion group (CI group) and DI groups were infused with normal saline. Heart rate (HR) and left ventricular systolic blood pressure (LVSP) were recorded at the beginning of mechanical ventilation,
$30 \mathrm{~min}$ of ischemia and at the end of reperfusion. At the end of $2 \mathrm{~h}$ of reperfusion, the rats were sacrificed, and the brains of the rats were quickly removed by craniotomy. The expression levels of brain cell autophagy-related proteins beclin-1, Phosphorylated mammalian target of rapamycin (p-mTOR) and mechanistic target of rapamycin (mTOR) were detected by Western blot. Statistical Package for the Social Sciences (SPSS) 19.0 software was used for statistical processing, quantitative data were expressed in the form of mean \pm standard deviation $(\mathrm{x} \pm \mathrm{s})$, and independent sample $t$ test was used for comparison between the two groups. One-way Analysis of variance (ANOVA) was used for comparison among groups. There was no statistically significant difference in HR and LVSP of rats in each group before left coronary artery ligation. HR and LVSP were significantly lower in CI group, DI group, $\mathrm{CI}+\mathrm{P}$ group and $\mathrm{DI}+\mathrm{P}$ group than before ligation, which was statistically significant $(p<0.05)$; Compared with the CI group, the increase of HR and LVSP in the $\mathrm{CI}+\mathrm{P}$ group at the end of $2 \mathrm{~h}$ after reperfusion was statistically significant $(\mathrm{p}<0.05)$, while compared with the DI group, the increase of HR and LVSP in the CI+P group at the end of $2 \mathrm{~h}$ after reperfusion was statistically significant $(p<0.05) \quad($ Table 1$)$. Compared with the normal rat with sham operation group (CC group), the expression level of p-mTOR in the other groups decreased, and the expression levels of beclin-1 and mTOR increased, which was statistically significant $(p<0.05)$. Compared with the CI group, the expression level of p-mTOR in the CI+P group increased, and the expression levels of beclin-1 and mTOR decreased, which were statistically significant $(\mathrm{p}<0.05)$. Compared with the DI group, the expression level of $\mathrm{p}$-mTOR increased, and the expression levels of beclin-1 and mTOR in the DI+P group, which was statistically significant $(p<0.05)$ (Table 2, fig. 1). Autophagy is a widespread normal physiological process, which refers

TABLE 1: COMPARISON OF HR AND LVSP IN EACH GROUP ( $x \pm s)$

\begin{tabular}{|c|c|c|c|c|c|}
\hline Index & Group & Number & Before ligation & 30 min before ischemia & End of $2 \mathrm{~h}$ reperfusion \\
\hline \multirow[b]{3}{*}{ HR } & $\mathrm{CC}$ & 6 & $423 \pm 11$ & $436 \pm 23$ & $425 \pm 17$ \\
\hline & $\mathrm{Cl}$ & 6 & $419 \pm 18$ & $353 \pm 27$ & $268 \pm 128$ \\
\hline & $\mathrm{Cl}+\mathrm{P}$ & 6 & $425 \pm 17$ & $382 \pm 10$ & $380 \pm 12$ \\
\hline \multirow{3}{*}{ (Times/min) } & $\mathrm{DC}$ & 6 & $421 \pm 16$ & $434 \pm 26$ & $422 \pm 9$ \\
\hline & DI & 6 & $419 \pm 19$ & $378 \pm 32$ & $218 \pm 110$ \\
\hline & $\mathrm{DI}+\mathrm{P}$ & 6 & $420 \pm 10$ & $359 \pm 30$ & $252 \pm 36$ \\
\hline \multirow[b]{3}{*}{ LVSP } & $\mathrm{CC}$ & 6 & $121 \pm 12$ & $125 \pm 6$ & $125 \pm 19$ \\
\hline & $\mathrm{Cl}$ & 6 & $120 \pm 10$ & $106 \pm 5$ & $85 \pm 7$ \\
\hline & $\mathrm{Cl}+\mathrm{P}$ & 6 & $124 \pm 9$ & $101 \pm 7$ & $92 \pm 6$ \\
\hline \multirow{3}{*}{$(\mathrm{mmHg})$} & DC & 6 & $125 \pm 8$ & $121 \pm 8$ & $115 \pm 9$ \\
\hline & $\mathrm{DI}$ & 6 & $125 \pm 9$ & $98 \pm 5$ & $69 \pm 7$ \\
\hline & $\mathrm{DI}+\mathrm{P}$ & 6 & $123 \pm 11$ & $99 \pm 4$ & $79 \pm 5$ \\
\hline
\end{tabular}


TABLE 2: THE EXPRESSION LEVELS OF BECLIN-1, mTOR AND p-mTOR IN EACH GROUP OF RATS

\begin{tabular}{lcccc}
\hline Group & Number & Beclin-1 & mTOR & P-mTOR \\
\hline CC & 6 & $19.08 \pm 0.08$ & $1.14 \pm 0.05$ & $1.26 \pm 0.23$ \\
Cl & 6 & $74.09 \pm 0.34^{\mathrm{a}}$ & $1.38 \pm 0.09^{\mathrm{a}}$ & $0.53 \pm 0.04^{\mathrm{a}}$ \\
$\mathrm{Cl}+\mathrm{P}$ & 6 & $59.87 \pm 0.25^{\mathrm{ab}}$ & $1.24 \pm 0.04^{\mathrm{ab}}$ & $0.85 \pm 0.07^{\mathrm{ab}}$ \\
DC & 6 & $49.63 \pm 0.24^{\mathrm{a}}$ & $1.06 \pm 0.04^{\mathrm{a}}$ & $0.88 \pm 0.03^{\mathrm{a}}$ \\
DI & 6 & $91.48 \pm 0.40^{\mathrm{ab}}$ & $1.47 \pm 0.07^{\mathrm{ac}}$ & $0.72 \pm 0.05^{\mathrm{ac}}$ \\
DI+P & 6 & $36.02 \pm 0.16$ & $1.25 \pm 0.04^{\mathrm{ac}}$ & $0.83 \pm 0.05^{\mathrm{ac}}$ \\
\hline
\end{tabular}

Compared with CC group, ${ }^{a} p<0.05$; compared with $\mathrm{Cl}$ group, ${ }^{b} \mathrm{p}<0.05$; compared with DI group, ${ }^{c} \mathrm{p}<0.05$

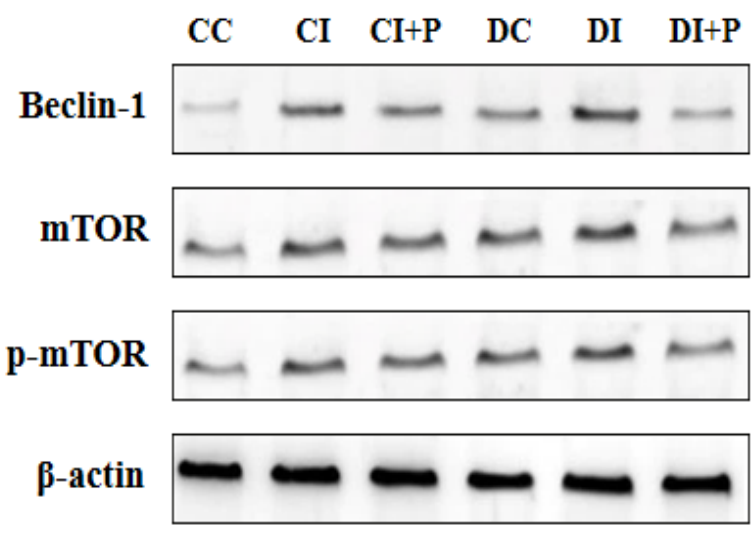

Fig. 1: The expression of $\beta$-actin, beclin-1, mTOR and p-mTOR protein in rat myocardial tissue

to the process of cell degradation of aging, damaged organelles and proteins by lysosomes under the regulation of autophagy related genes ${ }^{[3]}$. This process is a double-edged sword. Moderate autophagy is a defense mechanism of cells against the adverse environment, while excessive autophagy can lead to cell damage $\mathrm{e}^{[4]}$. Studies have shown that when brain cells are under ischemia and hypoxia, the expression of autophagyrelated proteins Beclin-1 and mTOR increases with autophagy being activated. Appropriate amount of autophagy can play a protective role on brain cells, while extensive autophagy leading by severe cerebral ischemia and hypoxia will damage the brain cell. In this study, there was no statistically significant difference in HR and LVSP of rats in each group before ligation. Compared with before ligation, the HR and LVSP of CI group, DI group, CI+P group and DI+P group decreased; indicating that myocardial ischemia reperfusion model was successfully prepared. Studies have shown that autophagy is involved in the pathophysiological process of type 2 diabetes. Autophagy plays an important role in cerebral ischemia ${ }^{[5]}$ and myocardial ischemiareperfusion $^{[6]}$. In this study, compared with the $\mathrm{CC}$ group, the expression of p-mTOR in the DC group decreased, and the expression levels of beclin-1 and mTOR increased, indicating that diabetes can activate autophagy and aggravate ischemia-reperfusion injury.
Propofol is a commonly used intravenous anesthetic ${ }^{[7]}$, which can improve the function of diabetic vascular endothelial cells and promote the expression of antiapoptotic proteins. There are researches confirming that ischemia-reperfusion and drug post-treatment in the remote region have an effect on the autophagy of brain cells and cardiomyocytes ${ }^{[8,9]}$, However, the effect of drug post-treatment on autophagy of brain cells after myocardial ischemia-reperfusion has not been reported at home and abroad. The results of this study showed that compared with the CI group, at the end of $2 \mathrm{~h}$ of reperfusion, the HR and LVSP of the CI+P group increased and that of the $\mathrm{DI}+\mathrm{P}$ group increased. Compared with the CI group, the expression level of p-mTOR increased, and the expression levels of beclin-1 and mTOR decreased in the $\mathrm{CI}+\mathrm{P}$ group; compared with the DI group, the expression level of p-mTOR increased, and the expression levels of beclin-1 and mTOR reduce in the DI $+\mathrm{P}$ group. It shows that propofol can reduce excessive autophagy and reduce brain cell damage after myocardial ischemia reperfusion in type 2 diabetic rats. In summary, when myocardial ischemiareperfusion occurs in type 2 diabetic rats, propofol can inhibit the excessive autophagy of brain cells in there by increasing its expression of p-mTOR and inhibiting the expression of mTOR, to reduce cerebral ischemiareperfusion injury in rats ${ }^{[10]}$.

\section{Acknowledgements:}

This work was supported by the Affiliated Hospital of Hebei University, Chu Han Wang and Wei Li contributed equally to this work.

\section{Conflict of Interests:}

The authors declared no conflict of interest.

\section{REFERENCES}

1. Chen X, Wang Y, Xiao ZY, Hou DN, Li DB, Zhang XP. Effect of propofol on myocardial ischemia/reperfusion injury in rats through JAK/STAT signaling pathway. Eur Rev Med Pharmacol Sci 2019;23:6330-8.

2. Lin C, Sui H, Gu J, Yang X, Deng L, Li W, et al. Effect and 
mechanism of propofol on myocardial ischemia reperfusion injury in type 2 diabetic rats. Microvasc Res 2013;90:162-8.

3. Kuma A, Komatsu M, Mizushima N. Autophagy-monitoring and autophagy-deficient mice. Autophagy 2017;13:1619-28.

4. Muriach M, Flores-Bellver M, Romero FJ, Barcia JM. Diabetes and the brain: oxidative stress, inflammation, and autophagy. Oxid Med Cell Longev 2014:102158.

5. Rami A, Langhagen A, Steiger S. Focal cerebral ischemia induces upregulation of Beclin 1 and autophagy-like cell death. Neurobiol Dis 2008;29:132-41.

6. Matsui Y, Takagi H, Qu X, Abdellatif M, Sakoda H, Asano T, et al. Distinct roles of autophagy in the heart during ischemia and reperfusion: roles of AMP-activated protein kinase and Beclin 1 in mediating autophagy. Circ Res 2007;100:914-22.

7. Walsh CT. Propofol: milk of amnesia. Cell 2018;175:10-3.

8. Wang Y, Qi X, Wang C, Zhao D, Wang H, Zhang J. Effects of propofol on myocardial ischemia-reperfusion injury in rats with type-2 diabetes mellitus. Biomed Rep 2017;6:69-74.
9. Andreka G, Vertesaljai M, Szantho G, Font G, Piroth Z, Fontos $\mathrm{G}$, et al. Remote ischaemic postconditioning protects the heart during acute myocardial infarction in pigs. Heart 2007;93:74952.

10. Sun B, Ou H, Ren F, Huan Y, Zhong T, Gao M, et al. Propofol inhibited autophagy through $\mathrm{Ca} 2^{+} / \mathrm{CaMKK} \beta / \mathrm{AMPK} /$ mTOR pathway in OGD/R-induced neuron injury. Mol Med 2018;24:1-1.

This is an open access article distributed under the terms of the Creative Commons Attribution-NonCommercial-ShareAlike 3.0 License, which allows others to remix, tweak, and build upon the work non-commercially, as long as the author is credited and the new creations are licensed under the identical terms

This article was originally published in a special issue, "Clinical Research in Pharmaceutical and Biomedical Sciences" Indian J Pharm Sci 2021:83(1)Spl issue1;89-92 